\title{
Power Quality Enhancement of Shunt Active Power Filter for Non-Linear Loads
}

\author{
Mahmoud M. Hussein \\ Faculty of Energy Engineering \\ Aswan University \\ Aswan 81528, Egypt \\ mahmoud_hussein@aswu.edu.eg
}

\author{
Mahmoud M. Hasseeb \\ Egyptian Electricity Transmission Company \\ Aswan 86, Egypt \\ mody_brave79@yahoo.com
}

\begin{abstract}
- in this paper, the power quality for three phase four wire non-linear load has been improved using different control types of shunt active power filter (SAF). The compensated (reference) current can be generated by the control algorithm and compared with filter injected current through a current controller to generate six pulses for driving IGBT. The source current should be sinusoidal and in phase with the voltage. Also the total harmonic distortion (THD) must be less than 5\% for meeting the IEEE standards 519-1992.
\end{abstract}

Index Terms-- current controller; control algorithms; power quality improvement; shunt active power filter, total harmonic distortion.

\section{INTRODUCTION}

The wide use of power electronics devices and non-linear loads leads to power quality deterioration of the system. Traditionally, passive filters can be used for compensation of harmonics and reactive power but they suffer from some demerits such as bulky size, resonance problems, its characteristics affected by source impedance, fixed compensation and particular compensation (i.e. they eliminate particular harmonic which is tuned to.). The shunt active power filter have been developed to overcome these problems [1]. The basic principle of the shunt active power filter as shown in Fig. 1 is that it generates a current equal and opposite in polarity to the harmonic current drawn by the load and injects it to the point of common coupling, thereby forcing the source current to be pure sinusoidal. Shunt APF is simple in construction, a voltage source inverter (VSI) shunted with a dc-link capacitor. The shunt APF is an effective solution to mitigate the harmonics, and therefore improving the power quality. Moreover, the performance of an APF system largely depends on the applied current control strategy for generating reference current. For the shunt APF to work satisfactorily, it should compensate harmonics under both balanced and unbalanced conditions [2]. The time domain methods are most widely used to generate the reference current for SAPF such as synchronous current detection method, power balance theory, generalized fryze algorithm, sinusoidal fryze algorithm I $\cos \phi$, synchronous reference frame method and instantaneous active and reactive power theory [3]. In this paper power balance theory and synchronous reference frame method used for extracting reference current.

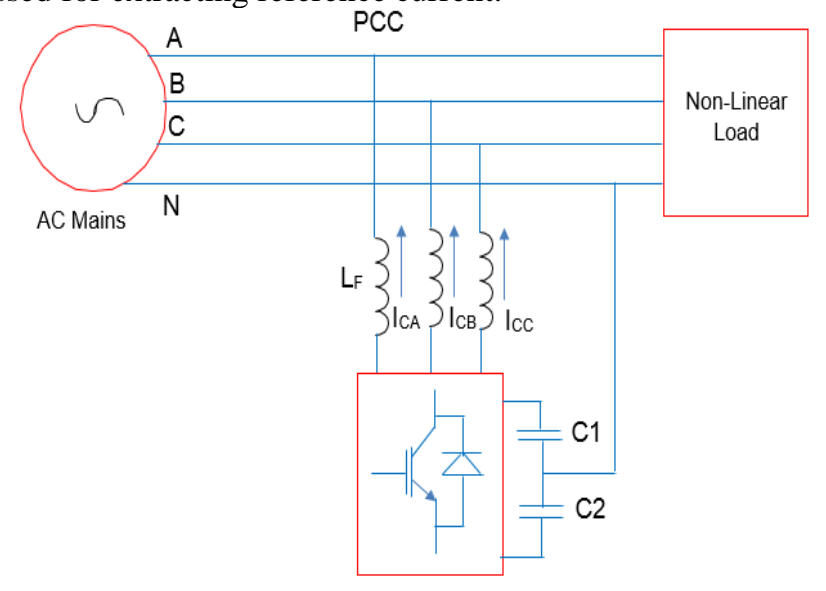

Fig.1 shunt active power filter construction.

\section{CURRENT CONTROLLERS}

A. Fixed hysteresis band current controller (FHCC)

The fixed hysteresis band current controller technique is suitable for all applications of voltage source converter [4-6], such as permanent magnet machines, grid connected systems and active power filters. It can be used for obtaining pulses to drive the IGBT as shown in Fig. 2. It has many advantages, such as very fast response with minimum hardware and software, simple extreme robustness and does not need any information about system parameters (independent load parameters). Its drawback is a variable switching frequency that causes acoustic noise and complex in design of input filters. The error (e) is obtained by subtracting the filter injected current from the reference current generated by the control algorithm. No switching occurs if the error is within the limits of the hysteresis band. If the error is out of the limits of the hysteresis band, the switching occurs.

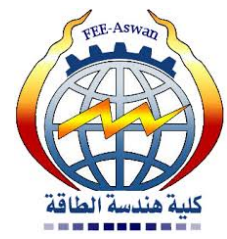




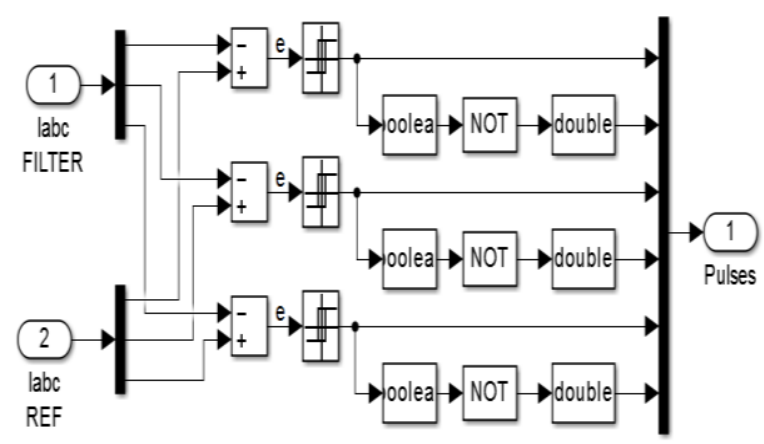

Fig. 2 Fixed hysteresis band current controller.

B. Sinusoidal Pulse Width Modulation (SPWM) Controller

This technique is called sin-triangle current controller. The reference wave $(\boldsymbol{e})$ is sin wave and the carrier wave is triangle wave. The reference wave can be obtained by subtracting the current injected by the filter from reference current generated by the control algorithm and applying it to PI controller. The PI controller used for removing lower order frequency and ripple in the reference wave (error signal). The error signal is compared with triangle wave to generate pulses for driving IGBT. The switching frequency of this technique is constant and is equal to the frequency of the triangle wave. The choice of values of $\boldsymbol{K}_{\boldsymbol{p}}$ and $\boldsymbol{K}_{i}$ are very important for good operation. Fig.3 illustrates the SPWM construction [7-9].

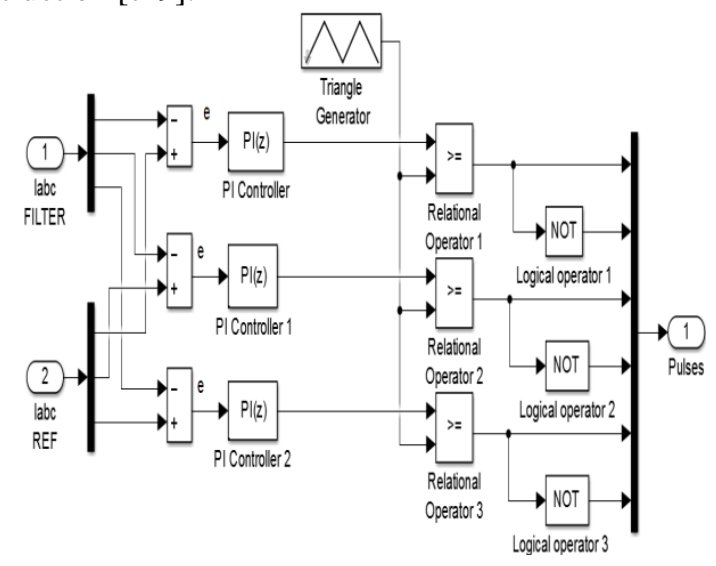

Fig.3 SPWM controller construction [9].

C. Adaptive hysteresis band current controller (AHCC)

The bandwidth considered as an important parameter in hysteresis current controllers. Changing it can be done by determining the maximum allowable ripple current [5-8]. Users can control the average switching frequency of the active power filter and deciding the performance for different hysteresis bandwidth values. Increasing the switching frequency of the inverter provides pure sinusoidal current waveform. The increasing limitations in switching frequency causes increasing in switching losses and electromagnetic interference (EMI) problems. Switching frequency used is based on reducing these factors (switching losses and EMI problems). The hysteresis band current control method is popularly used among the various PWM techniques because of its simplicity of implementation, fast response current control loop and inherently peak current limiting capability. The fixed hysteresis band has a disadvantage that the switching frequency varies within a band because peak -to- peak current ripple is required to be controlled at all points of fundamental frequency wave. However the adaptive hysteresis band current controller changes the hysteresis bandwidth according to instantaneous compensating current variation to minimize the influence of current distortion on the modulated waveform. Fig.4 shows PWM current and voltage waves for phase (a) of adaptive hysteresis band current controller. The current ia tends to cross the lower hysteresis band at point 1 , where the upper side of IGBT of leg "a" is switched on. The linearity rising current $i_{c a}^{+}$then touch the upper band at point 2, where the lower side IGBT of leg "a" is switched on as shown in Fig.5. From Fig.4 the following equations can be written in the respective switching intervals $\boldsymbol{t}_{\boldsymbol{l}}$ and $\boldsymbol{t}_{2}$.

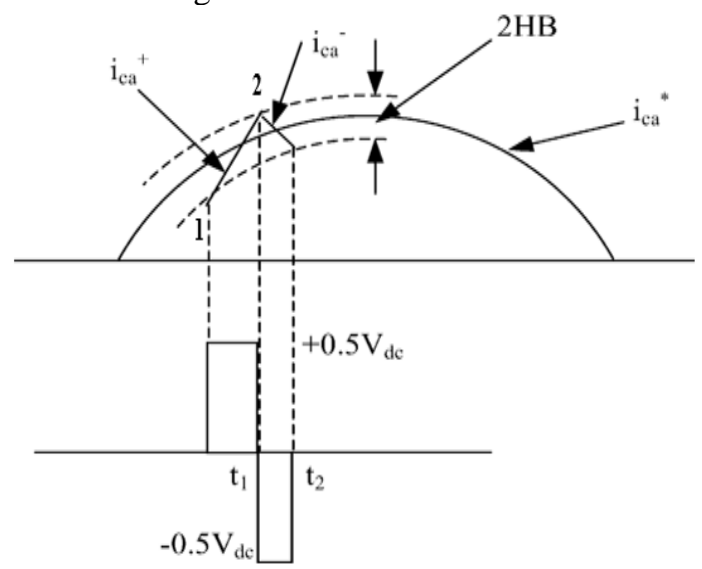

Fig.4 PWM current and voltage waves for phase (a) of adaptive hysteresis current controller.

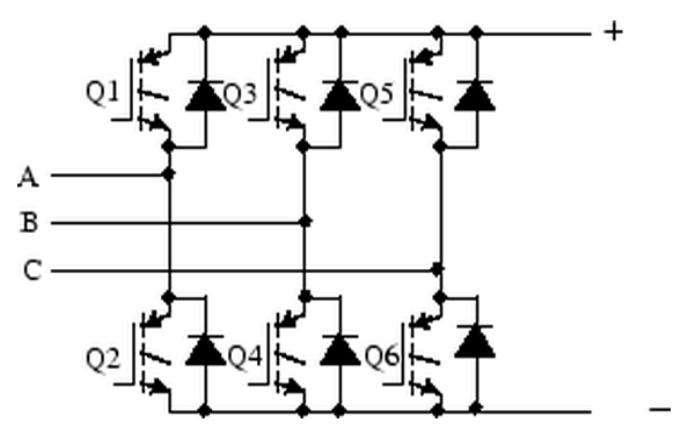

Fig.5 Construction of three phase (three legs) inverter.

$$
\begin{aligned}
\frac{d i_{c a}^{+}}{d t} & =\frac{1}{L}\left(0.5 V_{d c}-V_{s}\right) \\
\frac{d i_{c a}^{-}}{d t} & =\frac{-1}{L}\left(0.5 V_{d c}+V_{s}\right)
\end{aligned}
$$


From the geometry of Fig.2 the following equations can be written as:-

$$
\begin{aligned}
& \frac{d i_{c a}^{+}}{d t} t_{1}-\frac{d i_{c a}^{*}}{d t} t_{1}=2 H B \\
& \frac{d i_{c a}^{-}}{d t} t_{2}-\frac{d i_{c a}^{*}}{d t} t_{2}=-2 H B \\
& t_{1}+t_{2}=T_{c}=\frac{1}{f_{c}}
\end{aligned}
$$

Where $\boldsymbol{t}_{\boldsymbol{1}}$ and $\boldsymbol{t}_{2}$ are the respective switching intervals and $\boldsymbol{f}_{\boldsymbol{c}}$ is the switching frequency. By adding Eq.3 and Eq.4 and substituting in Eq.5, Eq.6 can be resulted as follows:-

$t_{1} \frac{d i_{a}^{+}}{d t}+t_{2} \frac{d i_{a}^{-}}{d t}-\frac{1}{f_{c}} \frac{d i_{c a}^{*}}{d t}=0$

Subtracting Eq.3 from Eq.4, Eq.7 can be written as follows:-

$$
4 H B=t_{1} \frac{d i_{c a}^{+}}{d t}-t_{2} \frac{d i_{c a}^{-}}{d t}-\left(t_{1}-t_{2}\right) \frac{d i_{c a}^{*}}{d t}
$$

By adding Eq.3 and Eq.4 and substituting in Eq.7, Eq.8 can be written as follows:-

$$
4 H B=\left(t_{1}+t_{2}\right) \frac{d i_{c a}^{+}}{d t}-\left(t_{1}-t_{2}\right) \frac{d i_{c a}^{*}}{d t}
$$

By substituting Eq.2 in Eq.6, Eq.9 can be written as follows:-

$$
t_{1}-t_{2}=\frac{\frac{d i_{c a}^{*}}{d t}}{f_{c} * \frac{d i_{c a}^{+}}{d t}}
$$

By substituting Eq.9 in Eq.9, The HB can be as follows:-

$$
H B=\left\{\frac{0.125 V_{d c}}{f_{c} L}\left[1-\frac{4 L^{2}}{V_{d c}^{2}}\left(\frac{v_{s}}{L}+m\right)^{2}\right]\right\}
$$

Where $f_{c}$ is switching frequency, $m=\frac{d i_{c a}^{*}}{d t}$ is the slope of command current wave. Equation indicates that the bandwidth of $(H B)$ that can be forced to get the required fixed switching frequency over a fundamental period. Therefore variable hysteresis bandwidth is a function of DC link voltage, phase voltage and slope of the reference current. For symmetrical operation of all three phases, it is expected that the hysteresis bandwidth $(H B)$ profiles $\boldsymbol{H B}_{\boldsymbol{a}}$, $\boldsymbol{H B}_{b}$ and $\boldsymbol{H B}_{\boldsymbol{c}}$ are the same but have phase difference.

\section{SAPF CONTROL ALGORITHMS}

A. Synchronous reference frame (SRF) method This algorithm has some advantages such as the rotating angle is calculated directly from the main voltages which makes this algorithm of frequency independent by avoiding the PLL in the control circuit. Consequently synchronization problems with unbalanced and distorted conditions of main voltages are also avoided. Fig. 6 shows block diagram of SRF method. The system voltage and load current are detected and transformed into $\alpha-\beta$ coordinates using the Clarck transformation as follows[10,11]:

$$
\begin{aligned}
& {\left[\begin{array}{l}
v_{0} \\
v_{\alpha} \\
v_{\beta}
\end{array}\right]=\sqrt{\frac{2}{3}}\left[\begin{array}{ccc}
\frac{1}{\sqrt{2}} & \frac{1}{\sqrt{2}} & \frac{1}{\sqrt{2}} \\
1 & -\frac{1}{2} & -\frac{1}{2} \\
0 & \frac{\sqrt{3}}{2} & -\frac{\sqrt{3}}{2}
\end{array}\right]\left[\begin{array}{l}
v_{a} \\
v_{b} \\
v_{c}
\end{array}\right]} \\
& {\left[\begin{array}{l}
i_{0} \\
i_{\alpha} \\
i_{\beta}
\end{array}\right]=\sqrt{\frac{2}{3}}\left[\begin{array}{ccc}
\frac{1}{\sqrt{2}} & \frac{1}{\sqrt{2}} & \frac{1}{\sqrt{2}} \\
1 & -\frac{1}{2} & -\frac{1}{2} \\
0 & \frac{\sqrt{3}}{2} & -\frac{\sqrt{3}}{2}
\end{array}\right]\left[\begin{array}{l}
i_{a} \\
i_{b} \\
i_{c}
\end{array}\right]}
\end{aligned}
$$

The load currents in $d-q$ coordinates can be calculated as follows:-

$\left[\begin{array}{l}i_{d} \\ i_{q}\end{array}\right]=\frac{1}{\sqrt{v_{\alpha}^{2}+v_{\beta}^{2}}}\left[\begin{array}{cc}v_{\alpha} & v_{\beta} \\ -v_{\beta} & v_{\alpha}\end{array}\right]\left[\begin{array}{l}i_{\alpha} \\ i_{\beta}\end{array}\right]$

$i_{d}=i_{d}^{-}+i_{d}^{\sim}$

(14)

$$
i_{q}=i_{q}^{-}+i_{q}^{\sim}
$$

The first one is DC component and the second is AC component. The DC component can be obtained using a second order low pass filter (cut-off frequency $=50 \mathrm{~Hz}$ ) and the AC component can be obtained using high-pass filter (cut-off frequency $=50 \mathrm{~Hz}$ ). The control strategy can guarantee balanced and sinusoidal source current at unity power factor. So the AC part of direct component and the whole current in quadrature component are the reference current of shunt active power filter that must be compensated.

$$
\left[\begin{array}{l}
i_{c \alpha} \\
i_{c \beta}
\end{array}\right]=\frac{1}{\sqrt{v_{\alpha}^{2}+v_{\beta}^{2}}}\left[\begin{array}{cc}
v_{\alpha} & -v_{\beta} \\
v_{\beta} & v_{\alpha}
\end{array}\right]\left[\begin{array}{c}
i_{d}^{-}-p_{\text {Loss }} \\
i_{q}
\end{array}\right]
$$

The reference current in $a b c$ coordinates can be calculated using the inverse of clarck transformation as follows:-

$$
\left[\begin{array}{l}
i_{a}^{*} \\
i_{b}^{*} \\
i_{c}^{*}
\end{array}\right]=\sqrt{\frac{2}{3}}\left[\begin{array}{ccc}
\frac{1}{\sqrt{2}} & 1 & 0 \\
\frac{1}{\sqrt{2}} & -\frac{1}{2} & \frac{\sqrt{3}}{2} \\
\frac{1}{\sqrt{2}} & -\frac{1}{2} & -\frac{\sqrt{3}}{2}
\end{array}\right]\left[\begin{array}{c}
i_{0} \\
i_{c \alpha} \\
i_{c \beta}
\end{array}\right]
$$




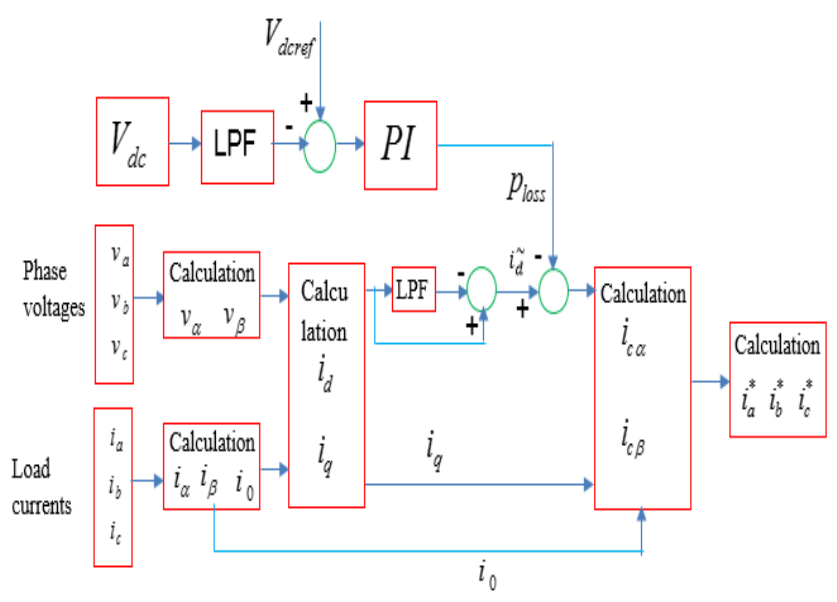

Fig.6 Block diagram of synchronous reference frame (SRF) method.

B. Power Balance Theory (PBT):

For calculating the reference supply current, Point Common Coupling (PCC) voltages $\left(V_{a}, V_{b}, V_{c}\right)$, load currents $\left(i_{a}, i_{b}, i_{c}\right)$ and DC voltage $\left(V_{d c}\right)$ of the filter are sensed. The control technique [12-14] is shown in Fig.7. The magnitude of the PCC voltages could be calculated as follows:-

$$
V_{t}=\sqrt{\frac{2\left(V_{a}^{2}+V_{b}^{2}+V_{c}^{2}\right)}{3}}
$$

Unity sin wave in phase with main voltages can be calculated as follows:-

$$
v_{a u}=\frac{v_{s a}(t)}{V_{t}}, \quad v_{b u}=\frac{v_{s b}(t)}{V_{t}}, \quad v_{c u}=\frac{v_{s c}(t)}{V_{t}}
$$

The consumed load active power will be calculated as follows:-

$$
\begin{aligned}
& P_{L}=V_{t}\left(i_{L a} v_{a u}+i_{L b} v_{b u}+i_{L c} v_{c u}\right) \\
& p_{L}=\bar{p}_{L}+\tilde{p}_{L}
\end{aligned}
$$

This instantaneous power has two components. The first is DC component and the second is alternating Component. The first component of load power could be obtained by using second order low- pass filter (cut- off frequency $=50$ $\mathrm{Hz}$ ). For power factor correction only the first component of the load consumed power must be supplied by the supply. The supply current $I_{s m}{ }^{*}$ has two components. First is $I_{s m p}{ }^{*}$ which is required for DC component of load consumed power and the second component is is $I_{\text {smd }}{ }^{*}$ which is required for the self-supporting DC bus voltage of the filter.

$$
\begin{aligned}
& I_{s m}^{*}=I_{s m p}^{*}+I_{s m d}^{*} \\
& I_{s m p}^{*}=\left(\frac{2}{3}\right) \frac{p_{L}^{-}}{V_{t}} \\
& I_{s m d}^{*}=K_{p} V_{d c}+K_{i} \int V_{d c e} d t
\end{aligned}
$$

Where $V_{d c e}=V_{d c}{ }^{*}-V_{d c}=$ error in DC bus voltage. $V_{d c}$ and $V_{d c}{ }^{*}$ are sensed and reference DC voltage of the filter respectively. $K_{p}$ and $K_{i}$ are the Proportional and Integral gains of PI controller over the DC bus voltage filter given in equation (24). Three phase reference of source current are calculated as:

$$
\begin{aligned}
& i_{s a}^{*}(t)=I_{s m}^{*} v_{a u} \\
& i_{s b}^{*}(t)=I_{s m}^{*} v_{b u} \\
& i_{s c}^{*}(t)=I_{s m}^{*} v_{c u}
\end{aligned}
$$

The compensating current could be obtained by subtract the load current from reference supply current as follows:

$$
\begin{aligned}
& i_{c a}(t)=i_{L a}(t)-i_{s a}^{*}(t) \\
& i_{c b}(t)=i_{L b}(t)-i_{s b}^{*}(t) \\
& i_{c c}(t)=i_{L c}(t)-i_{s c}^{*}(t)
\end{aligned}
$$

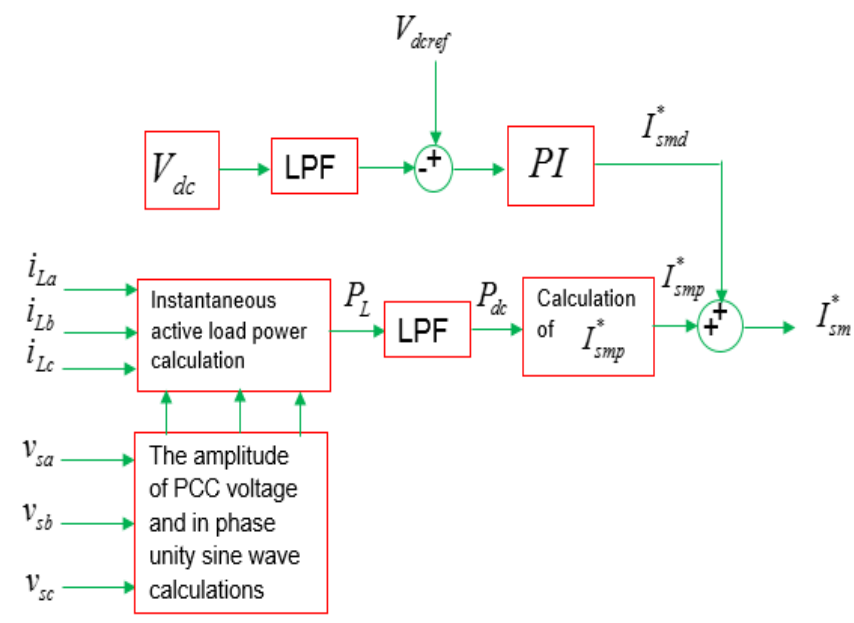

Fig.7 Block diagram of Power Balance theory.

\section{SimUlations ResUlts AND Disscutions}

Fig.8 shows the simulation block diagram of power circuit with shunt active power filter in Matlab Simulink. Table I. and Table II. Present the parameters of source, load and filter, respectively.

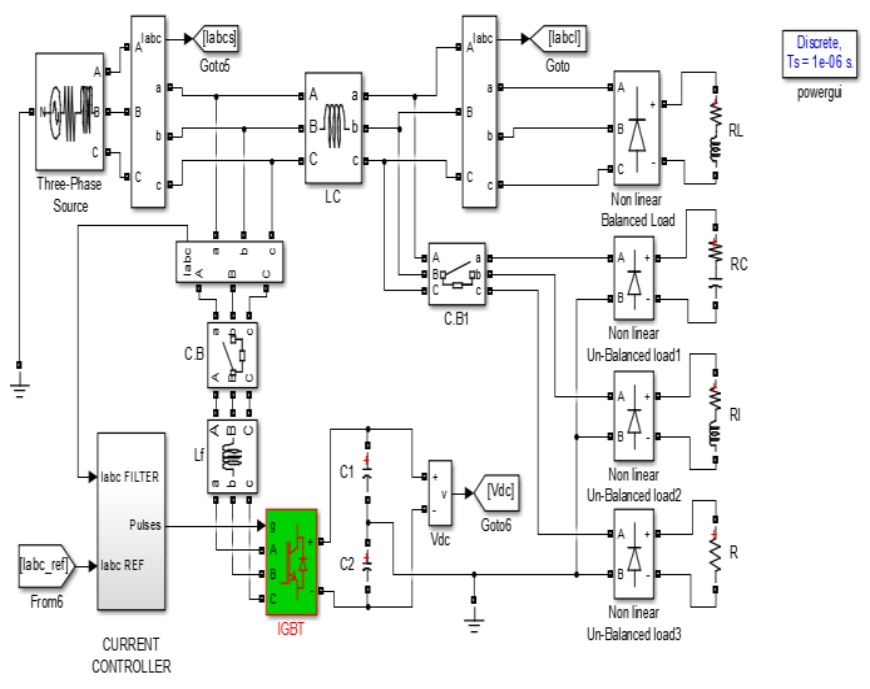

Fig.8 Power circuit block diagram with SAPF. 
TABLE I. SOURCE AND LOAD PARAMETERS [15].

\begin{tabular}{|l|l|}
\hline \multicolumn{2}{|c|}{ Non - linear Balanced load } \\
\hline$R$ load & \multicolumn{1}{|c|}{$30 \Omega$} \\
\hline$L$ load & $30 \mathrm{mH}$ \\
\hline \multicolumn{2}{|c|}{ Non - linear unbalanced load } \\
\hline$R_{a}$ & $50 \Omega$ \\
\hline$C_{a}$ & $1000 \mu \mathrm{F}$ \\
\hline$R_{b}$ & $50 \Omega$ \\
\hline$L_{b}$ & $20 \mathrm{mH}$ \\
\hline$R_{c}$ & $50 \Omega$ \\
\hline Source voltage & $220 \mathrm{~V} \mathrm{rms}$ \\
\hline System frequency & $50 \mathrm{HZ}$ \\
\hline Source resistance & $0.01 \Omega$ \\
\hline Source inductance & $1.0 \mu \mathrm{H}$ \\
\hline Load side inductance $L_{C}$ & $0.002 \mathrm{H}$ \\
\hline
\end{tabular}

TABLE II. FILTER PARAMETERS [15].

\begin{tabular}{|l|c|}
\hline Reference DC voltage $\mathrm{V}_{\mathrm{dc}}{ }^{*}$ & $650 \mathrm{~V}$ \\
\hline Filter inductance $\mathrm{L}_{\mathrm{f}}$ & $0.002 \mathrm{H}$ \\
\hline Inverter Capacitance $\mathrm{C}_{\mathrm{l}}=\mathrm{C}_{2}$ & $1100 \mu \mathrm{F}$ \\
\hline Frequency of triangle & $10 \mathrm{kHz}$ \\
\hline$K_{p}$ and $K_{i}$ for SPWM & 50 and 0.005 \\
\hline Switching frequency & $276 \mathrm{kHz}$ \\
\hline Ripple current & $0.0813 \mathrm{~A}$ \\
\hline
\end{tabular}

The main components of this system can be discussed as follows:-

The power supply is three single phase with rms voltage $(220 \mathrm{~V} / 50 \mathrm{~Hz})$, star connection and series $R L$ circuit $(R=0.01$ $\Omega, L=10 \mu \mathrm{H})$.

The simulated loads are two sets of non-linear loads. The first one is balanced three- phase uncontrolled diode rectifier supplying RL load which is connected from the start of the simulation. The second load is unbalanced three-phase uncontrolled diode rectifier which is connected at time is 0.6 sec using the three-phase circuit breaker supplying $R C$ load for phase A, $R L$ load for phase $\mathrm{B}$ and $R$ load for phase C. The used parameters of the non-linear load and filter for the simulation are indicated in Tables I and II respectively. Fig.9 shows source voltage and Figs.10 and 11 presents the source current in case of balanced and unbalanced load before the filter connection which is non- sinusoidal current so we should use active power filter to make this current sinusoidal to decrease the total harmonic distortion.

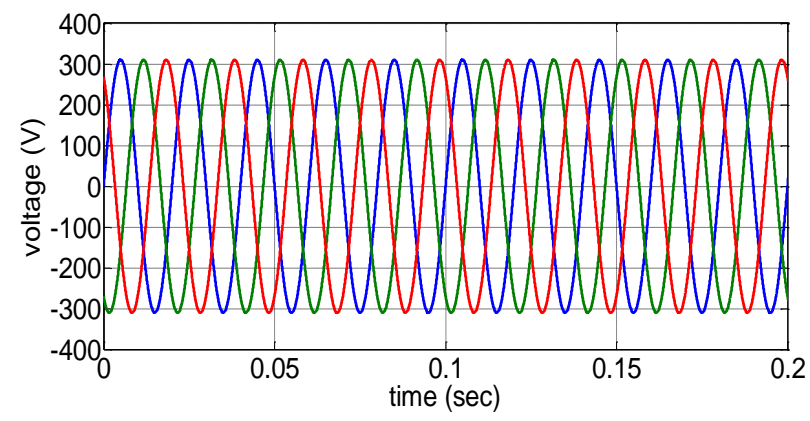

Fig.9 source voltage.

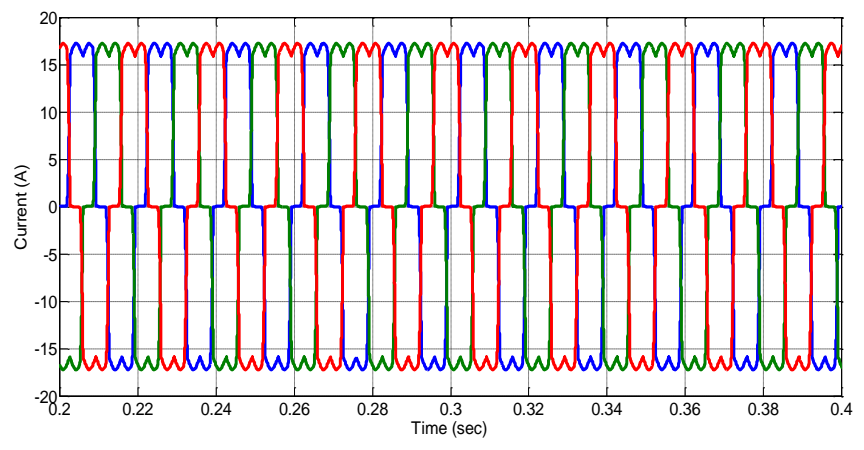

Fig.10 Source current in case of balanced load.

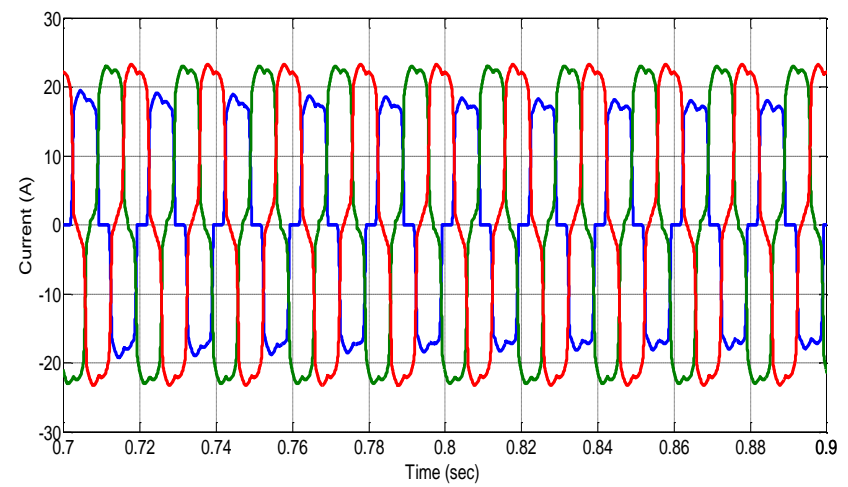

Fig.11 Source current in case of unbalanced load.

Table. III indicates the percentage values of THD for studied Load.

TABLE III. Percentage values of THD for studied load

\begin{tabular}{|l|l|}
\hline \multicolumn{3}{|c|}{$\%$ (THD) for Non - linear Balanced load } \\
\hline Phase $A$ \% (THD) for Non - linear unbalanced load \\
\hline Phase $A$ & 25.26 \\
\hline Phase $B$ & 18.4 \\
\hline Phase $C$ & 19 \\
\hline
\end{tabular}

Figs.12 and 13 show the instantaneous reactive power and neutral current before the filter connection.

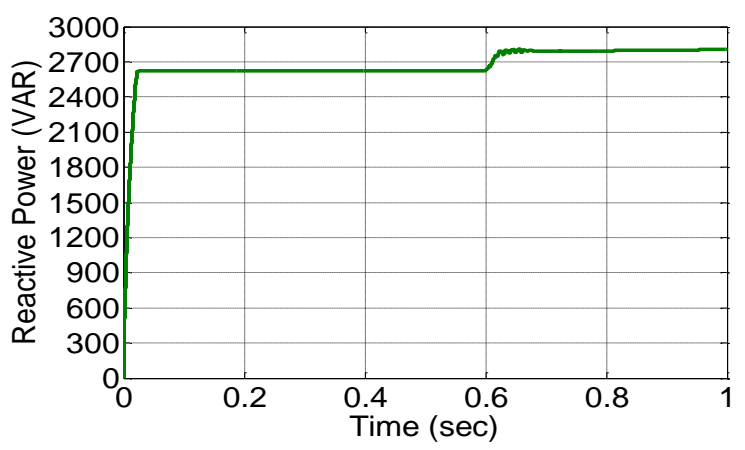

Fig.12 Reactive power before compensation. 


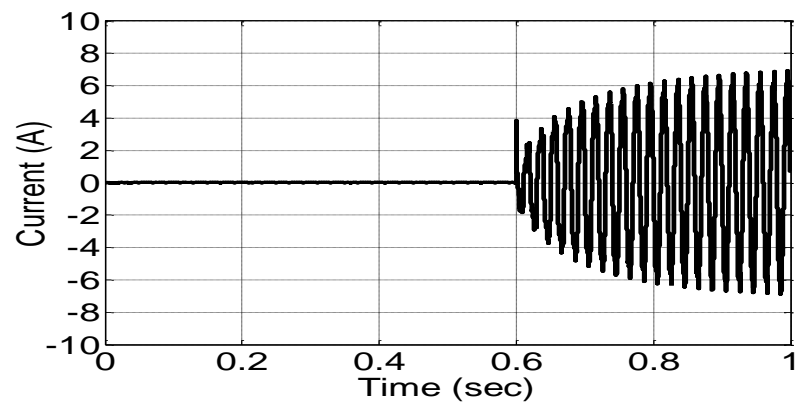

Fig.13 Neutral current before compensation.

When the filter connected the source current will be sinusoidal and in phase with the voltage as indicated in Figs.14-17

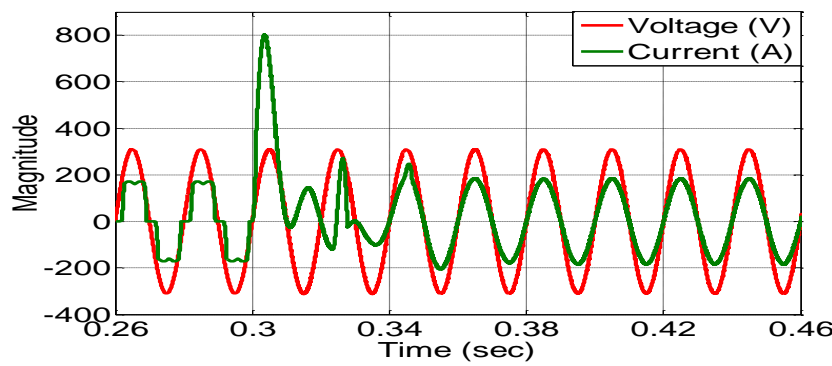

Fig.14 Source current using $S R F$ in case of balanced load

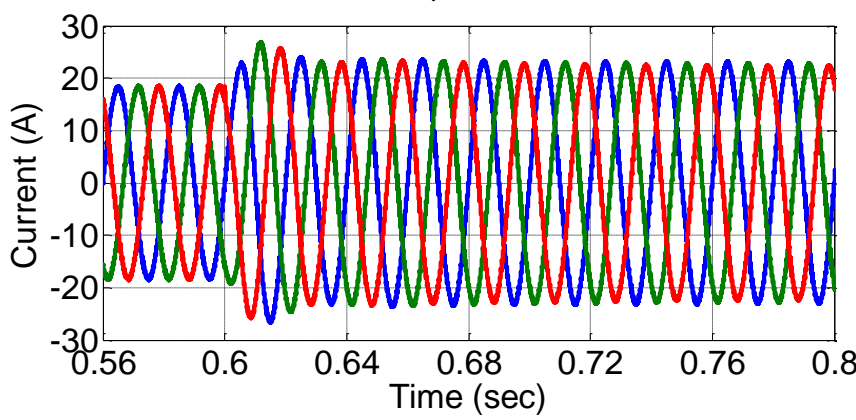

Fig.15 Source current using $S R F$ in case of un-balanced load.

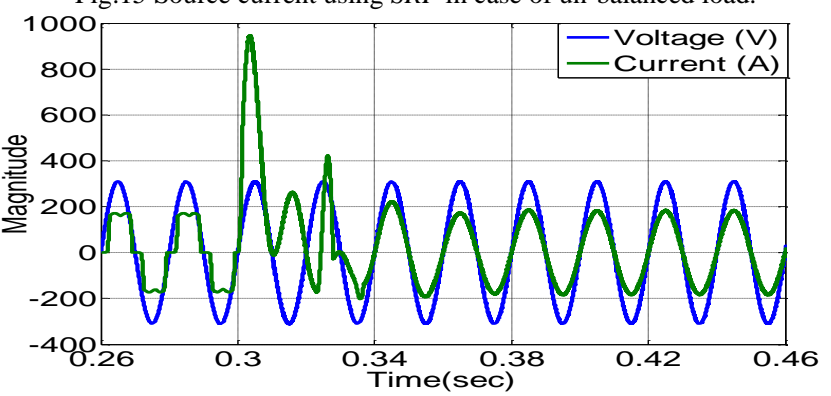

Fig.16 Source current using $P B T$ in case of balanced load.

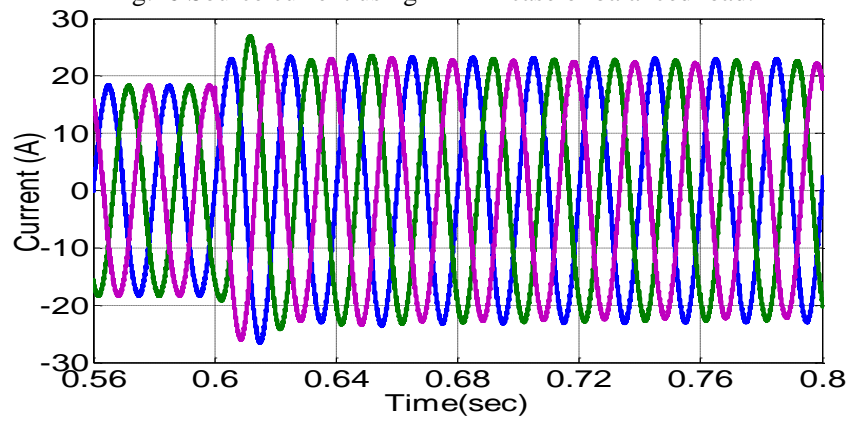

Fig.17 Source current using PBT in case of un- balanced load.
From Figs. 14 and 16, it can be observed that the current takes 0.05 and $0.04 \mathrm{sec}$ respectively to be sinusoidal, so the Power balance theory is better than Synchronous reference frame method. Table IV and VI indicate the percentage values of THD in case of balanced and un-balanced load respectively which below 5\% according to IEEE standard [16]. Also from these tables the SPWM current controller gives the best operation.

TABLE.IV Percentage values of THD of source current with different control algorithms and current controllers in case of balanced non-linear load.

\begin{tabular}{|l|l|l|l|}
\hline Control Algorithm & \multicolumn{3}{|c|}{ Current Controllers } \\
\cline { 2 - 4 } & FHCC & AHCC & $\begin{array}{c}\text { SP } \\
\text { W } \\
\text { M }\end{array}$ \\
\hline Power balance theory (PBT). & 1.05 & 0.85 & 0.81 \\
\hline $\begin{array}{l}\text { Synchronous reference } \\
\text { Frame (SRF) theory. }\end{array}$ & 0.93 & 0.81 & 0.79 \\
\hline
\end{tabular}

TABLE.VI Percentage values of THD of source current with different control algorithms and current controllers in case of un- balanced non-linear load.

\begin{tabular}{|l|l|l|l|}
\hline Control Algorithm & \multicolumn{2}{|l|}{ Current Controllers } \\
\cline { 2 - 4 } & FHCC & AHCC & $\begin{array}{l}\text { SPW } \\
\text { M }\end{array}$ \\
\hline Power balance theory (PBT). & 1.26 & 1.24 & 1.23 \\
\hline $\begin{array}{l}\text { Synchronous reference } \\
\text { Frame (SRF) theory. }\end{array}$ & 1.26 & 1.23 & 1.22 \\
\hline
\end{tabular}

Fig. 18 shows DC output voltage with control algorithms.

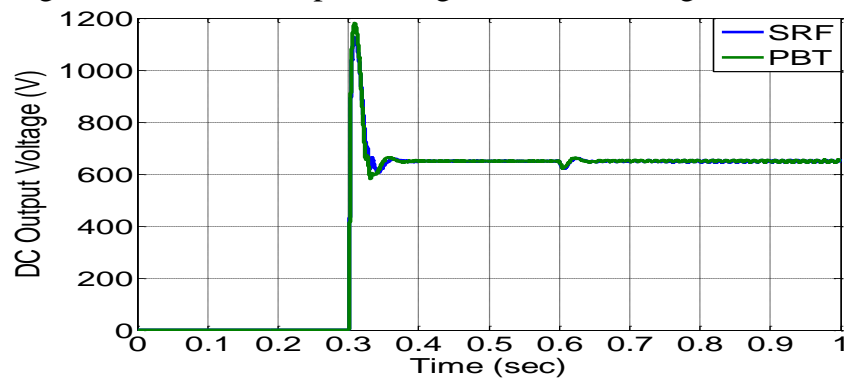

Fig.18 DC output voltage with control algorithms.

The value of neutral currents that produced of unbalanced loads can be cancelled with using the shunt active power filter as indicated in Figs. 19 and 20.

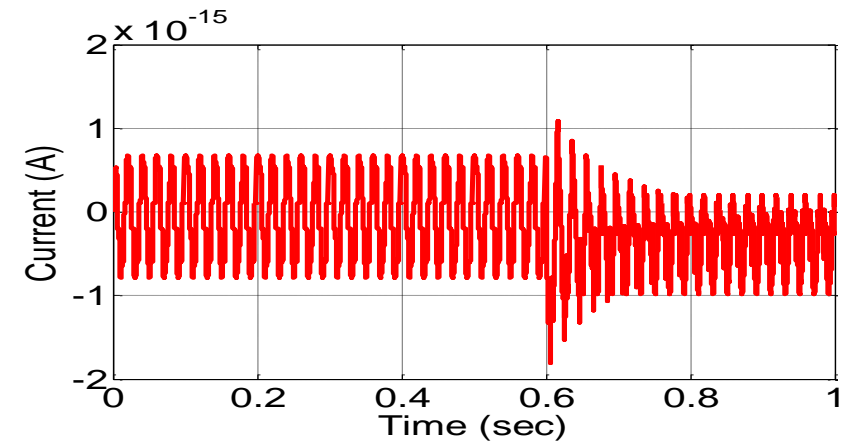

Fig.19 Nuetral current using SRF control algorithm. 
International Journal of Applied Energy Systems, Vol. 2, No. 2, July 2020

ISSN: 2636 - 3712 (Printed Version) ISSN: 2636 - 3720 (Online Version)

Special Issue: ICEE-2019

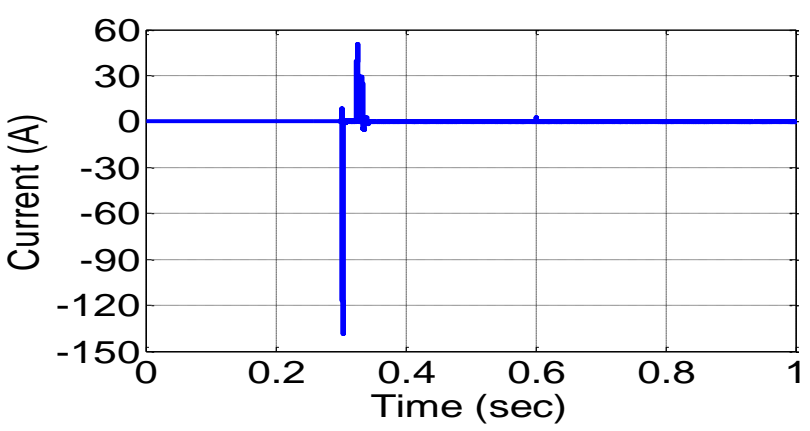

Fig.20 Nuetral current using PBT control algorithm.

Also reactive power can be compensated using shunt active power filter with different control algorithms and current controllers as shown in Figs. 21 and 22 respectively.

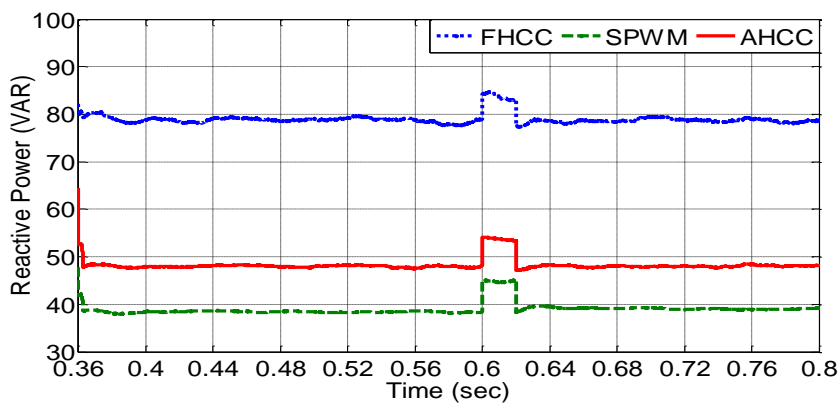

Fig. 21 Reactive power using PBT algorithm with different current controllers.

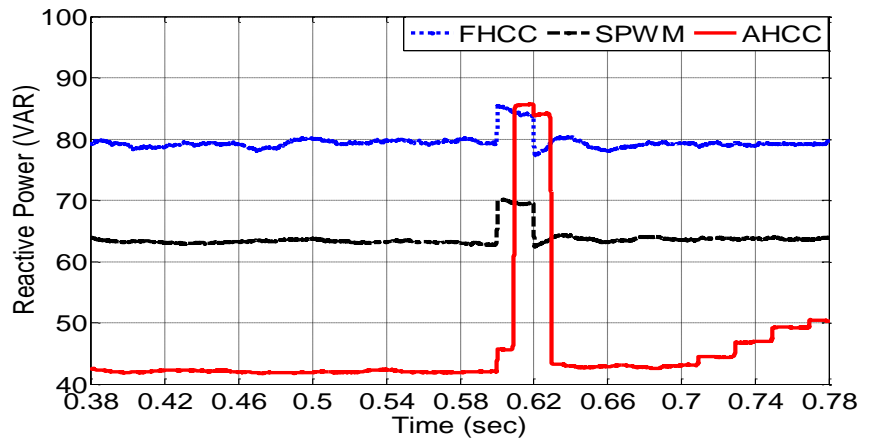

Fig. 22 Reactive power using SRF algorithm with different current controllers.

\section{CONCLUSIONS}

The control of shunt active power filter has been presented in this paper to enhance the power quality of three phase four wire nonlinear loads. The source current becomes sinusoidal and in phase with voltage, total harmonic distortion below $5 \%$ according IEEE standards, reduced reactive power and neutral current near zero. It can be seen that the SPWM current control technique gives the best result in reduction of THD. Also the current in power balance theory becomes sinusoidal faster than SRF.

\section{REFERENCES}

[1] Shyamsundar Jena, Rahul KumarGupta and B.Chitti Babu" Comparative study between different control strategies for shunt active power filter"1st National Conference on Power Electronics System \& Application PESA 2013.

[2] M.Rama Gopal, Sobharani Yarangula "Simulation and analysis of shuntActive power filter for power quality improvement" international journal of advanced trends in computer science and Engineering. Vol.3, No.1, Pages: 26-31 (2014).

[3] H.Abaali, M.T. Lamchich, and M. Raoufi "A Compensation of Shunt Active Power Filter Control Methods under Non-Sinusoidal and Unbalanced Voltage Conditions" International Journal of Electrical, computer, Energetic and Communication Engineering vol: 8.No:8, 2014.

[4] Chennai Salim, Benchouia M-T,"Three - phase three wire shunt active power filter based on hysteresis, fuzzy and MLPNN controllers to compensate current harmonics" Journal of electrical and control engineering Vol.3 No.3, , pp.6-12 American V-king Scientific Publishing,2013.

[5] Papan Dey and Saad Mekhilef "Current Controllers of Active Power Filter For power Quality, AUTOMATIKA 56,pp. 42-54,2015.

[6] Shashibhushan R.Shahu, Nikhil A.Wanjari, "Performance Analysis of Shunt Active Power Filter with Various Switching Signal Generation techniques" International Journal of Engineering Development and Research(IJEDR), Vol.5 Issuse.2,pp 1795-1802, 2017.

[7] Murat Kale and Engin Ozdemir "An adaptive hysteresis band current controller for shunt active power filter" ELSEVIER JOURNAL, Vol.73, pp113-119 June 2004.

[8] M.Ramya,M.Sathyapriya,A.Benazir Hajira,P.Kumar" Mitigation of line Current Harmonics Using Shunt Active Filter with Instantaneous Real and Reactive Power Theory "Journal of Electrical and Electronics Engineering. Vol.9, pp59 -67, 2014.

[9] Consalva J. Msigwa, Beda J.Kundy and Bakari M.M.Mwinyiwiwa " Control algorithm for shunt active power filter using synchronous reference frame theory" international journal of electrical and computer engineering,Vol.3, No 10, pp 1822-1828,2009.

[10] Charles. S , Member, IACSIT , G. Bhuvaneswari " Comparison of three phase shunt active power filter algorithms" International journal of computers and Electrical Engineering Vol. 2 No. 1, pp. 175-180, February 2010 .

[11] Mikkili Suresh, Anup Kumar Panda , Y.Suresh " Fuzzy Controller Based three phase four wire Shunt Active Filter for Mitigation of Current Harmonics with Combined P-Q and Id - Iq control Strategies" Scientific Research Journal pp 43-52, February 2011.

[12] Gaber Shabib, Mahmoud M. Hussein and Mahmoud Mohammed Hasseeb "Harmonics Mitigation Techniques for Shunt Active Power Filter Control" Journal of Engineering and Applied Science (JEAS), Faculty of Engineering, Cairo University, Vol.65, Issue.6, 2018.

[13] Gaber Shabib, Mahmoud M. Hussein and Mahmoud Mohammed Hasseeb "Comparative Study of Different Control Algorithms of Shunt Active Power Filter for Non-Linear Loads" 2017 Nineteenth International Middle East Power Systems Conference (MEPCON), Menoufia University, Egypt, 19-21 December 2017.

[14] A. Rohani ,M.Joorabian " Modeling and control of DSTATCOM using Adaptive hysteresis band current controller in three -phase four wire Distribution systems." The 5th power electronics, drives systems and Technologies conference"(PEDSTC 2014), Feb 5-6, 2014, Tehran Iran.

[15] Goerge adam , alina G. stan and gheorghe livint "matlab Simulink approach to shunt active power filters" proceeding 25th European conference on modelling and Simulink, united states,2011.

[16] IEEE Recommended Practices and Requirements for Harmonics control in Electrical power systems. IEEE STD.519-1992. 